\title{
Earth's Diminishing Magnetic Dipole Moment is Driving Global Carbon Dioxide Levels and Global Warming
}

\author{
David A. E. Vares ${ }^{1,2}$, Michael A. Persinger ${ }^{1,2,3}$ \\ ${ }^{1}$ Human Studies, Laurentian University, Sudbury, Canada \\ ${ }^{2}$ Behavioural Neuroscience Programs, Laurentian University, Sudbury, Canada \\ ${ }^{3}$ Biomolecular Sciences, Laurentian University, Sudbury, Canada \\ Email: $\underline{\mathrm{dx} \text { vares@laurentian.ca, mpersinger@laurentian.ca }}$
}

Received 13 June 2015; accepted 4 August 2015; published 7 August 2015

Copyright (C) 2015 by authors and Scientific Research Publishing Inc.

This work is licensed under the Creative Commons Attribution International License (CC BY). http://creativecommons.org/licenses/by/4.0/

(c) (1) Open Access

\begin{abstract}
Although there are powerful models that couple human activity with elevated atmospheric carbon dioxide levels and global warming, the relationships are still based upon correlations rather than causation. Consequently, there is always the probability of a third factor that produces both. Analyses of the diminishing magnetic dipole moment of the earth and the increased carbon dioxide levels and global temperature within the last 40 years revealed correlations of $\mathbf{- 0 . 9 9}$ and $\mathbf{- 0 . 9 0}$, respectively. This powerful association has been reported by other researchers. Why it has been ignored by the scientific community is not clear. The sources of the shift in average geomagnetic (magnetic dipole) intensity have not been identified but these relatively rapid decreases and increases have occurred historically with onsets of periods of warming and cooling, including glacier formation. If the long-time quasi-periodicity of the earth's magnetic dipole moment is coupled to alterations in solar activity as the system moves around the galactic center, then attribution of elevated carbon dioxide-temperature to human sources rather than actual etiologies can be counterproductive to adaptation.
\end{abstract}

\section{Keywords}

$\mathrm{CO}_{2}$, Global Warming, Geomagnetic Field, Magnetic Dipole, Energy, Quantification

\section{Introduction}

The earth is a complex of spatial phenomena whose configurations vary globally and locally and whose tempor-

How to cite this paper: Vares, D.A.E. and Persinger, M.A. (2015) Earth's Diminishing Magnetic Dipole Moment Is Driving Global Carbon Dioxide Levels and Global Warming. International Journal of Geosciences, 6, 846-852. 
al interconnections occur within seconds to centuries. The states of the gases and fluids that constitute the atmosphere and oceans are coupled ultimately to solar fluctuations but with variable latencies that produce extraordinarily complex correlations. The recent apparent coupling between positive drifting of carbon dioxide levels and global temperatures has been attributed to anthropogenic sources by various sophisticated models [1]-[3]. Pictorially, it is driven by the visually conspicuous positive correlation between global temperature and atmospheric $\mathrm{CO}_{2}$. However, there are equally compelling and powerful quantitative associations between the recent diminishment of the earth's magnetic dipole and the increase in both global temperature and $\mathrm{CO}_{2}$ that should be examined.

The consensus of opinion regarding the increases in global temperature as causally connected to anthropogenic sources of $\mathrm{CO}_{2}$ is primarily based upon models rather than quantitative or multivariate analyses of actual data. Because the variables are not experimentally manipulated, even a strong association is still a correlation with the possibility that a third factor produces both changes. Several authors have shown that during the same period as the slow increase in global temperature, the solar corona has expanded and related interplanetary parameters have changed [4]-[7]. The global warming apparently occurring on Mars $\left(0.7^{\circ} \mathrm{C}\right.$ over 20 years $)$ that is concurrent with terrestrial increases in temperature [8] is more consistent with sources within the solar system than human activities. El-Borie et al. [9] [10] and Persinger [11] [12] reiterated the slow increase in the amplitude of geomagnetic activity coupled to the solar coronal expansion and how quantitatively the resulting additional energy within the atmosphere and the upper layers of the oceans could elevate temperature to the values associated with global warming. Gang and Persinger [13] demonstrated the predicted effect sizes between geomagnetic activity and thermal changes in seawater within a persistently monitored locality.

However, there is still a major potential geophysical source for the carbon dioxide-global temperature connection that has been largely ignored. This is strong coupling with the recent decrease in earth's magnetic dipole moment and average geomagnetic field intensity. There is clear secular variation of the geomagnetic main field [14] which occurs within time frames of years to centuries. Courtillot et al. [15] reviewed the relationship among the earth's static magnetic field variations, global temperature and $\mathrm{CO}_{2}$ concentration in the atmosphere. They noted the archaeomagnetic "jerks" or abrupt approximately $15 \%-30 \%(\sim 100 \mathrm{yr})$ changes in global geomagnetic intensity. Global cooling was associated with increases in geomagnetic field intensity whereas global warming was associated with decreased geomagnetic field intensity. They observed that the correlation between geomagnetic intensity and temperature disconnected after the mid 1980s when global temperature continued while solar irradiance and geomagnetic activity declined. It is important to always differentiate among changes in total magnetic dipole (geomagnetic) intensity which constitutes about $90 \%$ of the main field vs. geomagnetic activity that is coupled classically to primarily solar changes.

Pazur and Winklhofer [16] examined the potential source for this apparent contradiction. They found that the solubility of air in sea water was $15 \%$ lower when the average static magnetic field was $20 \mu \mathrm{T}$ compared to the typical $50 \mu \mathrm{T}$. The effect upon $\mathrm{CO}_{2}$ solubility by this magnetic effect was twice as large and sufficient to modulate the carbon exchange between the atmosphere and oceans. They estimated that a $1 \%$ decrease in the earth's magnetic dipole moment contained the potential to release the $\mathrm{CO}_{2}$ by more than a factor of 10 compared to subaerial volcanism. Although they stated that the effect was diminutive compared to anthropogenic sources, their data indicated that only an $8 \%$ decrease in dipole moment between the years 1850 and 2000 was associated with a global temperature increase of $1.2^{\circ} \mathrm{C}$. This effectively constitutes the "global warming" around which mathematical models are constructed. Here we extend this research and show that the increase in $\mathrm{CO}_{2}$ and decline in average geomagnetic intensity (the inference of magnetic dipole moment) are coupled so strongly. They are effective identities.

\section{Data Sources and Methods of Analyses}

Annual total field intensities (F) as measured in nanoTesla (nT) were retrieved from the United States Geological Survey (USGS), Boulder Observatory (BOU) (http://geomag.usgs.gov/) for the years between 1964-2012. Annual Globally Averaged $\mathrm{CO}_{2}(\mathrm{ppm})$ levels were retrieved from the National Oceanic \& Atmospheric Administration (NOAA) Earth System Research Laboratory (ESRL) (http://www.esrl.noaa.gov/) for the years between 1980 and 2012. The Annual Global (Land and Ocean combined) Anomalies (degrees C) expressed as departures from the 20th century average (1901-2000) measures were retrieved from the National Oceanic \& Atmospheric Administration (NOAA) National Centers for Environmental Information (NCEI) (https://www.ncdc.noaa.gov/) 
(formerly the National Climatic Data Center (NCDC)), for the years between 1970 and 2012.

The annual data were entered into SPSS software for investigation of statistical relationships. The BOU total field intensity measures $(\mathrm{N}=49)$ had a grand annual average value of $54755.53( \pm 1041.25) \mathrm{nT}$, the globally averaged $\mathrm{CO}_{2}$ measures $(\mathrm{N}=33)$ had a grand annual average value of $363.56( \pm 16.26) \mathrm{ppm}$, and the global temperature anomalies $(\mathrm{N}=43)$ had a grand annual average of $0.3344^{\circ} \mathrm{C}( \pm 21)^{\circ} \mathrm{C}$ departures from the century average. Zero-order relationship analyses were conducted on the three annual measures.

\section{Results}

The results were compelling. Figure 1 shows the relationship between the decline in average geomagnetic field intensity (dipole moment) in $\mathrm{nT}$ and increase in globally averaged $\mathrm{CO}_{2}$ in ppm between the years 1970 and 2012. The scattergram showing the correlation between these two variables is shown in Figure 2. The correlation approaches 1 and the shared variance is effectively $100 \%$. A $\sim 2500 \mathrm{nT}$ decrease was associated with a $\sim 50 \mathrm{ppm}$ increase in $\mathrm{CO}_{2}$ over this period.

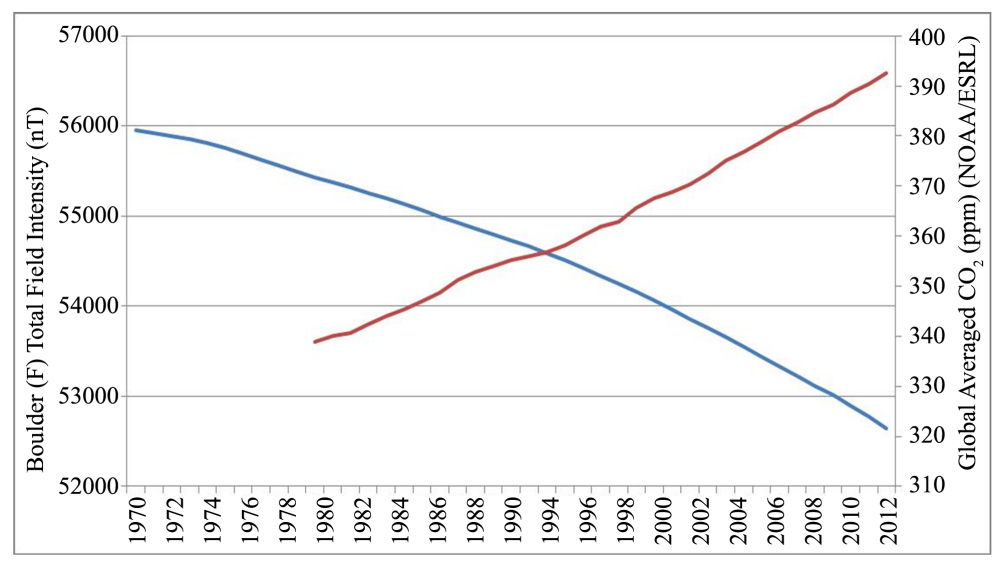

Figure 1. The decline of the intensity of the total magnetic field strength of the earth (blue line) and increase in Global Averaged carbon dioxide levels in the atmosphere.

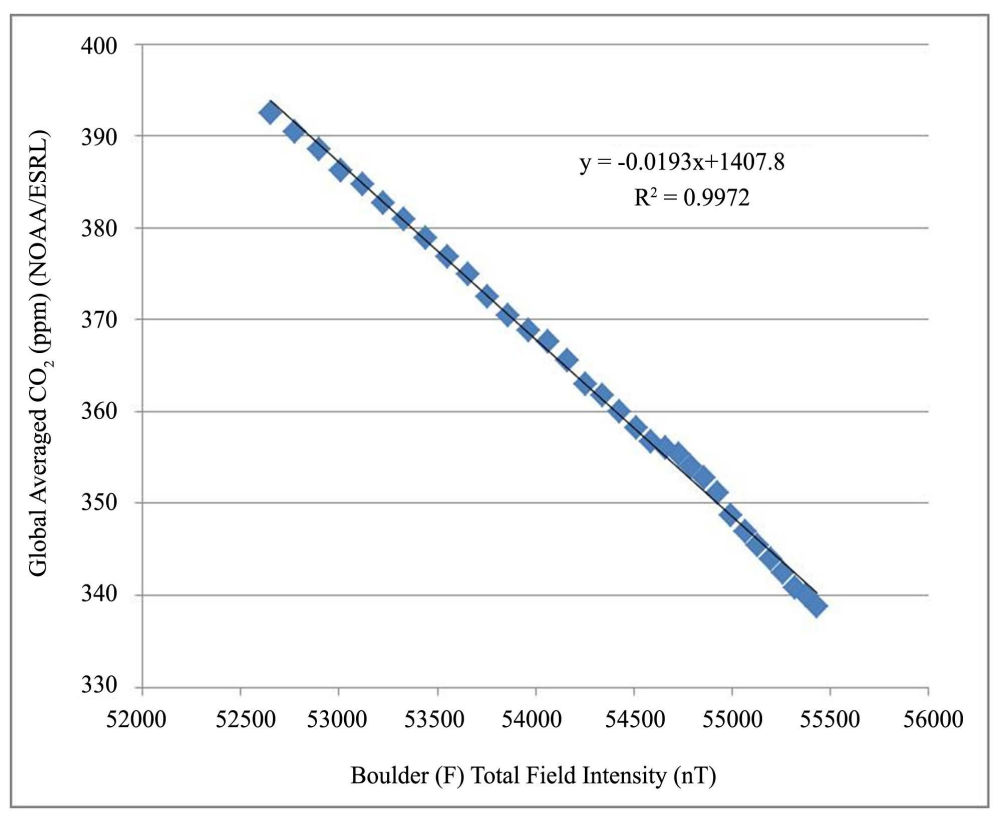

Figure 2. Correlation and regression line for the inverse correlation between the global concentrations of atmospheric carbon dioxide and the total magnetic field intensity. 
Figure 3 shows the changes over time between the annual global temperature and the diminishing averaged geomagnetic field intensity. Figure 4 shows the scattergram of the association. Approximately $82 \%(r=0.91)$ of the variance is shared between the shift in average geomagnetic intensity and the global land and ocean temperatures.

\section{Discussion and Conclusions}

If changes in global temperature are like most other complex processes, there is likely to be multiple contributions that can combine and cancel in unusual or even unpredictable patterns. The reviewed consensus at present is that global warming and climate change are due almost exclusively to human activity or anthropogenic sources [1]-[3]. The conclusion leads to both geopolitical and national policy decisions that affect the perspective of billions of people, often at the expense of the full scientific method. However, despite sophisticated modeling, the causal connection between elevated $\mathrm{CO}_{2}$ levels in the atmosphere and global warming is still a correlation. The algorithms for multiple regression models are implicitly structured such that when two variables are regressed

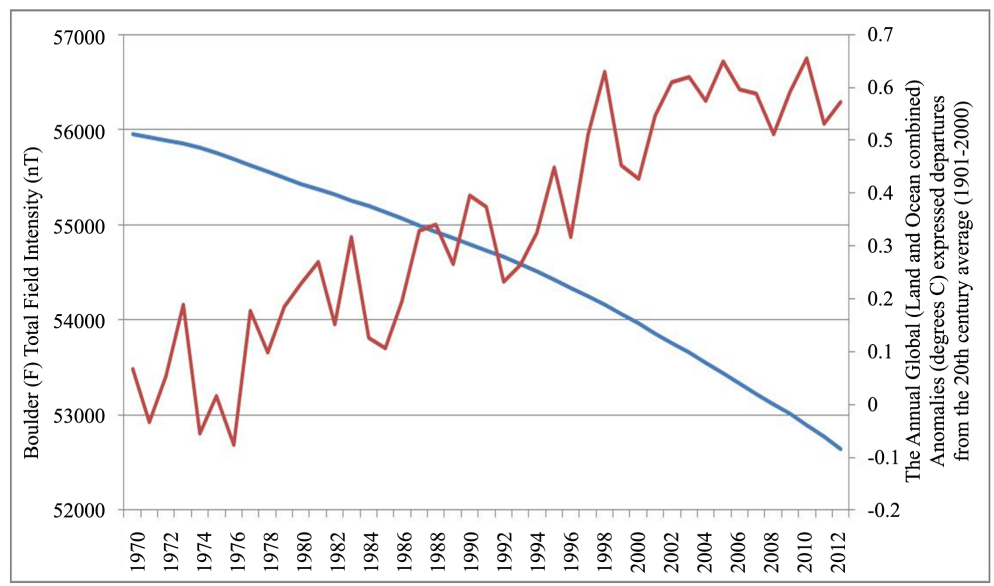

Figure 3. The decline in the earth's magnetic field intensity (blue) and increase in annual global ocean and land temperatures (red) over the last 40 years.

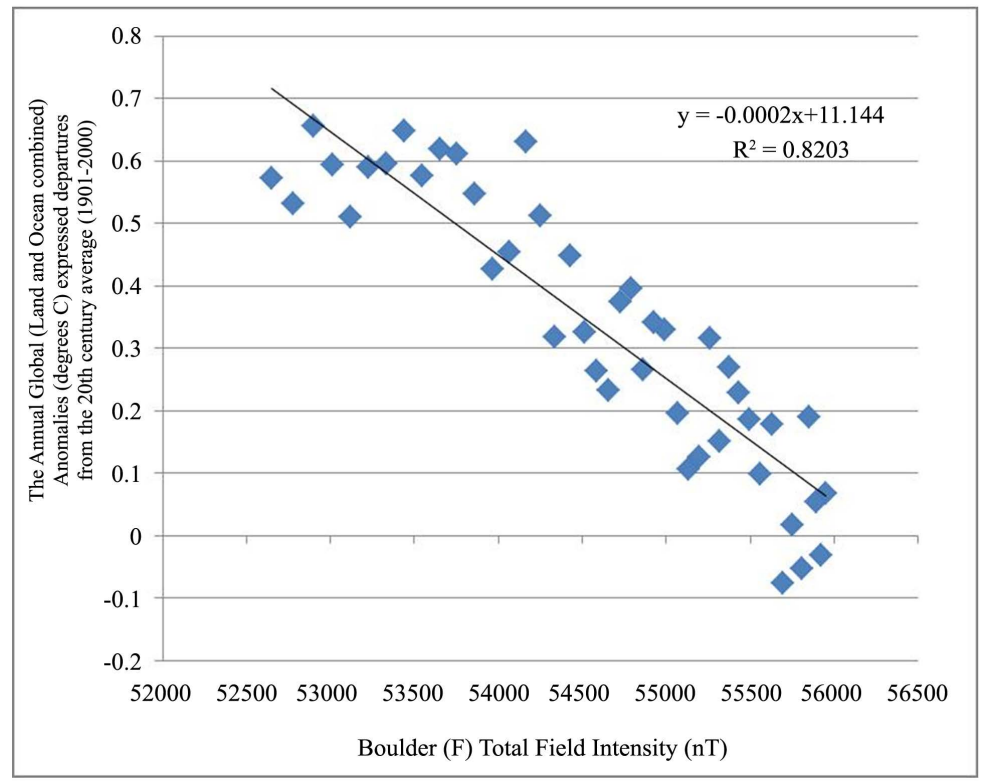

Figure 4. Scatterplot and regression line for the inverse correlation between global temperature and change in the inference of the earth's magnetic dipole. 
against each other the pair with the least standard error of the estimate is often considered the causal direction. This assumes that both variables share similar numerical moments such as central tendencies, dispersions and skewness. This is not applicable to the $\mathrm{CO}_{2}$-global temperature changes over time. The differences in the sizes of the coefficients of variation for the measures, such as $\mathrm{CO}_{2}$ from primarily a sample of volcanic sources, compared to the global temperature estimates from a larger sample of latitude-varying stations, are significant. Hence, pictorial aesthetics more than quantitative validity often influences the viewer's interpretation of causal direction.

The limit of any correlational relationship between two variables is that there is always the probability a third variable is causing both. El-Borie and his colleagues [9] [10] and Persinger [11] [12] who examined the increasing values of the geomagnetic activity (not the earth's magnetic dipole) as inferred by the aa indices over the last century indicated that a significant proportion of increases in global temperatures could be associated with the magnetic energy available within the large terrestrial volumes. Other researchers [15] [16] have indicated as well that although consensual interpretations consider human-related origins as the major causes of global warming, there are other contributing sources. The diminishing magnetic dipole strength of the earth and the correlative increase in $\mathrm{CO}_{2}$ release as measured experimentally by Pazur and Winklhaufer [16] have been most prominent.

Secular variation of the main magnetic field of the earth is assumed to originate from the earth's core. The origins of these changes are likely to be multivariate but coherent sources. The axial dipole moment that dominates the main geomagnetic field does not contribute, according to Ryskin's [17] elegant quantification, to the axial-dipole coefficients of secular variation. He develops the possibility that the magnetic field is induced by the electrically conductive capacity of the ocean as it flows through the earth's main field contributes to secular variation. However, the variation in ocean flow measured in Megatons per second and secular variations of 10 to $50 \mathrm{nT}$ per year (between the years 1950 and 2005) was not associated with a decline in the magnetic dipole values.

To be consistent with the data from major global sources, shown in Figures 1-4 (rather than by mathematical models), we propose that the increased atmospheric $\mathrm{CO}_{2}$ does not cause global warming but rather both have been caused by the consequences of the diminished magnetic field strength of the earth. There is quantitative support for this suggestion. Between 1980 and 2012 the concentrations of $\mathrm{CO}_{2}$ in the atmosphere had increased by $\sim 50 \mathrm{ppm}$ and the change in the earth's magnetic field strength had decreased by $\sim 2.9 \times 10^{-6} \mathrm{~T}$. The traditional equation for energy from a magnetic field is:

$$
E=\frac{\beta^{2}}{2 \mu} \mathrm{m}^{3}
$$

where $\beta$ is the strength of the field, $\mu$ is the magnetic susceptibility $\left(4 \pi \times 10^{-7} \mathrm{~N} \cdot \mathrm{A}^{-2}\right)$ and $\mathrm{m}^{3}$ is the volume. For convenience, if we assume a $10 \mathrm{~km}$ depth for the contributing component from the oceans and a $10 \mathrm{~km}$ height for the functional atmosphere, the volumes can be approximated by the differences between the earth's spherical shell radius and this $10^{4} \mathrm{~m}$ thickness. The value would be $\sim 5.1 \times 10^{18} \mathrm{~m}^{3}$. Therefore, the diminishment from a decrease of $2.9 \times 10^{-6} \mathrm{~T}$ over the approximately 32 year period would be $1.72 \times 10^{13} \mathrm{~J}$.

The increase in $\mathrm{CO}_{2}$ in the atmosphere has increased by $50 \mathrm{ppm}$ or $3 \times 10^{19}$ molecules per $22.7 \mathrm{~L}$ (a Mole, assuming STP) which is $0.13 \times 10^{22} \mathrm{CO}_{2}$ molecules per cubic meter. Within the volume of the atmosphere occupied by the $10 \mathrm{~km}$ shell there would be $0.67 \times 10^{40} \mathrm{CO}_{2}$ molecules. If the Pazur and Winklhaufer [16] data can be generalized to the global scale with respect to the differential effect of diminished magnetic field strength upon releasing $\mathrm{CO}_{2}$ from sea water, then most of the $\mathrm{CO}_{2}$ will originate from this source rather than exclusively human activity. Current estimates indicate that about $93 \%$ of $\mathrm{CO}_{2}$ is contained within the oceans.

Hence, the diminished energy within the $10 \mathrm{~km}$ shell of sea water from the decreasing global magnetic field intensity would be $1.72 \times 10^{13} \mathrm{~J}$ divided by $0.67 \times 10^{40} \mathrm{CO}_{2}$ or $2.56 \times 10^{-27} \mathrm{~J}$ per $\mathrm{CO}_{2}$ molecule. The implicit assumption for $\mathrm{J}$ conversions is the temporal unit of one second. If we assume the weaker covalent and hydrogen bonds that sequester the $\mathrm{CO}_{2}$ within the constituents of the sea water range between $\sim 0.2$ to $2 \times 10^{-20} \mathrm{~J}$, this means a decline of energy for about $10^{-7}$ to $10^{-8} \mathrm{~s}$ per molecule on average occurred over the total period. This duration (tens of nanoseconds) would be within the range required for $\mathrm{CO}_{2}$ to escape the surface tension of water and for the weaker hydrogen bonds to oscillate in water. Ocean-atmosphere carbon cycle models estimate the exchange of dissolved $\mathrm{CO}_{2}$ with equilibrium partial pressure of $\mathrm{CO}_{2}$ in the ocean, partial pressure in the air, and the gas exchange coefficient [18]. The estimated gas exchange coefficient is dependent upon a number of envi- 
ronmental variables (e.g. wind-speed) and according to the scientific literature range between 8 and 18 $\mathrm{mol} \cdot \mathrm{m}^{-2} \cdot \mathrm{yr}^{-1}$. Assuming the ocean surface area of $3.35 \times 10^{14} \mathrm{~m}^{2}$, the 33 years for the $50 \mathrm{ppm} \mathrm{CO}_{2}$ increase and the $0.67 \times 10^{40} \mathrm{CO}_{2}$ molecules, there would be a net excess of $+1 \mathrm{~mol} \cdot \mathrm{m}^{-2} \cdot \mathrm{yr}^{-1}$ between the ocean and atmosphere carbon cycle. This value is well within the range of model-estimated variance.

If the $\mathrm{CO}_{2}$ increases into the atmosphere from the sea water because of the diminished magnetic field are associated with the increased temperature, then that energy should translate into an equivalent temperature. Applying the classic definition that $4.18 \mathrm{~J}$ is required to increase $1 \mathrm{cc}\left(10^{-6} \mathrm{~m}^{3}\right)$ of water $1{ }^{\circ} \mathrm{C}$ at STP, then the total energy within the $5.1 \times 10^{18} \mathrm{~m}^{3}$ will be $2.1 \times 10^{13} \mathrm{~J}$. With $1.72 \times 10^{13} \mathrm{~J}$ equivalence available from the change, the analogous temperature shift will be $1.2^{\circ} \mathrm{C}$. This implies that there is an equilibrium system by which the removal of the source energy is related quantifiably to the increase or decrease of the two connected variables. Thus, the equivalent value of the $1.2^{\circ} \mathrm{C}$ would be reflected in the increase due to the release of $\mathrm{CO}_{2}$.

There is one remaining feature of the magnetic dipole moment argument that should be addressed. What would be the potential causes of this alteration? The source of the main component of the geomagnetic field is attributed to the core. However, such mass is influenced potentially by the sun's mass. In addition, the solar system is always moving through a different space around the galactic center for which the complete orbit is about 250 million years. The potential interface for which an interaction may occur that can modulate very low amplitude variations in the magnetic dipole can be considered by equating the energy associated with the main dipole moment and the change in magnetic field intensity in a volume (1) by which energy is also calculated. Hence,

$$
m^{3}=\left[\frac{\left(A m^{2} \cdot T\right) 2 \mu}{T^{2}}\right]
$$

Assuming a dipole magnetic moment of $8 \times 10^{22} \mathrm{~A} \cdot \mathrm{m}^{2}$ and the change of $2.9 \times 10^{-6} \mathrm{~T}$, the volume would be 7 $\times 10^{22} \mathrm{~m}^{3}$. This volume would occupy about 6 earth radii. Although there are multiple events that occur at this distance, it is the minimum value for the closest approach of the compressed boundary of the magnetopause or the interface with the interplanetary magnetic field and potentially the expanding solar corona and its correlative interplanetary field [14]. Such an interface would offer an alternative explanation for the earth's magnetic dipole decline. If it is strongly coupled to the variables responsible for the expansion of the solar corona during the same period as the increase of global temperatures on earth and more recently similar elevated temperatures on Mars [8], then primary attribution of global warming to human activity rather than understanding the actual solar mechanisms may not be adaptable.

\section{Acknowledgements}

D.A.E.V. thanks Mark O. Vares for his insight and affirmation. M.A.P. thanks his intellectual mentor Harold C. Urey for the inspiration that arises from infinite possibilities.

\section{References}

[1] Allen, M.R., Gillett, N.P., Kettleborough, J.A., Hegerl, G., Schnur, R., Scott, P.A., Boer, G, Covey, C., Delworth, T.L., Jones, G.S., Mitchell, J.F.N. and Barnett, T.P. (2006) Quantifying Anthropogenic Influence on Recent Near-Surface Temperature Change. Surveys in Geophysics, 27, 491-544. http://dx.doi.org/10.1007/s10712-006-9011-6

[2] Huber, M. and Knutti, R. (2012) Anthropogenic and Natural Warming Inferred From Changes in Earth's Energy Balance. Nature Geoscience, 5, 31-36. http://dx.doi.org/10.1038/ngeo1327

[3] Cook, J., Nuccitelli, D., Green, S. A., Richardson, M., Winkler, B., Painting, R., Way, R., Jacobs, P. and Skuce, A. (2013) Quantifying the Consensus on Anthropogenic Global Warming in the Scientific Literature. Environmental Research Letters, 8, Article ID: 024024. http://dx.doi.org/10.1088/1748-9326/8/2/024024

[4] Lockwood, M. Stamper, R. and Wild, M.M. (1999) A Doubling of the Sun's Coronal Magnetic Field during the Past 100 Years. Nature, 399, 437-439. http://dx.doi.org/10.1038/20867

[5] Erlykin, A.D., Sloan, T. and Wolfendale, A.W. (2009) Solar Activity and the Mean Global Temperature. Environmental Research Letters, 4, Article ID: 014006. http://dx.doi.org/10.1088/1748-9326/4/1/014006

[6] Kristjansoon, J.E., Staple, A. and Kristiansen, A. (2002) A New Look at Possible Connections Between Solar Activity, Clouds and Climate. Geophysical Research Letters, 29, 2107-2111. http://dx.doi.org/10.1029/2002GL015646

[7] Stamper, R., Lockwood, M., Wild, M.N. and Clark, T.D.G. (1999) Solar Causes of the Long-Term Increase in Geo- 
magnetic Activity. Journal of Geophysical Research, 104, 325-328. http://dx.doi.org/10.1029/1999JA900311

[8] Fenton, L.K., Geissler, P.E. and Haberie, R.M. (2007) Global Warming and Climate Forcing by Recent Albedo Changes on Mars. Nature, 446, 646-649. http://dx.doi.org/10.1038/nature05718

[9] El-Borie, M.A. and Al-Thoyaib, S.S. (2006) Can We Use the aa Geomagnetic Activity Index to Predict Partially the Variability in Global Mean Temperatures? International Journal of Physical Sciences, 1, 67-74.

[10] El-Borie, M.A., Shafik, E., Abdel-Moneim Abdel-Halim, A. and Yourssri El-Monier, S. (2010) Spectral Analysis of Solar Variability and Their Possible Role on the Global Warming. Journal of Environmental Protection, 1, 111-116. http://dx.doi.org/10.4236/jep.2010.12014

[11] Persinger, M.A. (2009) The Possible Role of Dynamic Pressure From the Interplanetary Magnetic Field on Global Warming. International Journal of Physical Sciences, 4, 55-46.

[12] Persinger, M.A. (2010) The Cosmology of Climate Change: Interconnections Between Increased Global Temperature, Carbon Dioxide and Geomagnetic Activity. Journal of Cosmology, 8, 1957-1969.

[13] Gang, N. and Persinger, M.A. (2012) Correlations between Ocean Water Temperature and Related Parameters from the Victoria Experimental Network under the Sea (VENUS) and Geomagnetic Activity: Implications for Climate Change. International Journal of Physical Sciences, 7, 660-663.

[14] Campbell, W.H. (1997) Introduction to Geomagnetic Fields. Cambridge University Press, Cambridge.

[15] Courtillot, V., Gallet, Y., Le Mouel, J.-L., Fluteau, F. and Genevey, A. (2007) Are There Connections between the Earth's Magnetic Field and Climate? Earth and Planetary Science Letters, 253, 328-339. http://dx.doi.org/10.1016/j.eps1.2006.10.032

[16] Pazur, A. and Winklhofer, M. (2008) Magnetic Effect on $\mathrm{CO}_{2}$ Solubility in Seawater: A Possible Link Between Geomagnetic Field Variations and Climate. Geophysical Research Letters, 35, L16710. http://dx.doi.org/10.1029/2008GL034288

[17] Ryskin, G. (2009) Secular Variation of the Earth's Magnetic Field: Induced by the Ocean Flow? New Journal of Physics, 11, Article ID: 063015. http://dx.doi.org/10.1088/1367-2630/11/6/063015

[18] Siegenthaler, U. and Sarmiento, J.L. (1993) Atmospheric Carbon Dioxide and the Ocean. Nature, 365, 119-125. http://dx.doi.org/10.1038/365119a0 